\title{
Insulin therapy, weight gain and prognosis
}

\author{
Israel Hodish MD
}

Department of Internal Medicine, Division of Metabolism, Endocrinology and Diabetes, University of Michigan Medical Center, Ann Arbor, Michigan

\section{Correspondence}

Israel Hodish, MD, PhD, Department of Internal Medicine, Division of Metabolism, Endocrinology and Diabetes, University of Michigan, 1000 Wall Street 48105, Ann Arbor, Michigan

Email: ihodish@umich.edu

Funding information

None
Insulin therapy is mainly used by people with type 2 diabetes who have failed other therapies and have become insulin-deficient. This group represents about a quarter of all people with type 2 diabetes. Almost all those with type 2 diabetes who start insulin therapy or intensify it gain weight, which may potentially diminish the prognostic advantage of improved glycaemia. To date, all available guidelines emphasize both the attainment of glycated haemoglobin (HbA1c) goals and weight control, without directing the clinician as to which element is of a higher priority. The following review attempts to clarify the issue using the available literature. The body of evidence presented in this review indicates that glycaemic management with exogenous insulin replacement is of a much higher priority than weight gain. Lower weight or weight loss do not show prognostic benefit in advanced stages of diabetes; therefore, weight gain should not discourage providers from achieving and maintaining $\mathrm{HbA} 1 \mathrm{c}$ goals with insulin therapy, regardless of insulin dosage or other medications.

\section{KEYWORDS}

antidiabetic drug

\section{1 | INDEX CASE}

A 56-year-old man is referred to the endocrinology clinic to establish care. He has had type 2 diabetes for 17 years and has been using insulin therapy for the past 5 years. He currently uses a biphasic (premixed) insulin at a total daily dosage of 80 units. He also uses a full dose of metformin, a full dose of a glucagon-like peptide-1 receptor agonist (GLP-1RA) and a sodium-glucose co-transporter-2 (SGLT2) inhibitor. Despite these therapies, his glycated haemoglobin (HbA1c) has been high for the past 3 years, and is currently at $93 \mathrm{mmol} / \mathrm{mol}$ (10.6\%). His current body mass index (BMI) is $33 \mathrm{~kg} / \mathrm{m}^{2}$. Over the past decade he has gained $15 \mathrm{~kg}$, but over the past 3 years has lost $5 \mathrm{~kg}$. He has macroalbuminuria and currently excretes $>1 \mathrm{~g}$ albumin per $1 \mathrm{~g}$ creatinine. His current plasma creatinine level is mildly elevated at $1.2 \mathrm{mg} / \mathrm{dL}$. He was diagnosed with coronary artery disease 2 years ago without evidence of myocardial damage.

The patient presents a clinical dilemma. If we do not increase his insulin dosage, he may continue to lose weight as he has for the past 3 years. Is this weight loss catabolic or pharmacological? In other words, is he losing weight on his current medical regimen because of a deficiency in insulin availability, and thus a breakdown of fat and protein? Or is his weight loss the result of his current use of a GLP1RA agonist or SGLT2 inhibitor? Does it matter for the patient's overall prognosis?
Another option would be to increase insulin dosage. Improving insulin availability will probably reduce his average glucose level or $\mathrm{HbA1c}$, which will improve his prognosis. Yet, he will almost certainly gain weight. Will this weight gain undermine the therapeutic benefit of improving glycaemia? Moreover, increasing total daily insulin may put him at risk of developing more hypoglycaemia and of experiencing potentially severe hypoglycaemic events. How will this affect prognosis?

Which is the higher clinical priority, providing sufficient insulin or maintaining stable weight? To date, all available guidelines emphasize both the attainment of $\mathrm{HbA} 1 \mathrm{c}$ goals and weight control, without directing the clinician as to which element is of a higher priority: insulin replacement or stability in weight.

This dilemma is not only challenging but also exceedingly common. Type 2 diabetes is a heterogeneous group of conditions with a progressive course. Approximately a decade after the diagnosis, patients tend to become resistant to multiple pharmacological agents and become increasingly insulin-deficient. At this point, only exogenous insulin therapy can alleviate their hyperglycaemia. By that time, many have developed complications. ${ }^{1}$ People with type 2 diabetes who use insulin represent approximately one-quarter of the patient population. ${ }^{2,3}$ All over the Western world, most patients do not achieve recommended target $\mathrm{HbA} 1 \mathrm{c}$ values, and a third have $\mathrm{HbA1c}$ values $>75 \mathrm{mmol} / \mathrm{mol}(9 \%)^{1,4}$

The following review will attempt to bring clarity to the issue using the available literature. It is becoming clear that the growing weight of 
the entire population exceeds the capacity of the human endocrine pancreas ${ }^{5,6}$; however, the present review will only focus on individuals who have already acquired advanced type 2 diabetes. Prognosis in this review will be defined as overall survival or cardiovascular mortalityrelated survival. Advanced diabetes will be defined as type 2 diabetes treated with insulin. To refine the discussion, it will not encompass the aesthetic implications of weight, other therapeutic options or quality of life. Because bariatric surgery affects carbohydrate metabolism and potentially prognosis in a non-weight-related fashion (within hours of the intervention), it will not be discussed in this context. ${ }^{7}$ Given the multitude of quantifiable and non-quantifiable clinical variables involved, the review was not designed as a meta-analysis.

The discussion is divided into three subsections: (1) the relationship between insulin therapy and weight; (2) the relationship between weight and prognosis; and (3) the relationship between insulin therapy and prognosis.

The clinical question addressed by this review is: In patients with advanced diabetes, which element is of a higher priority: insulin replacement or weight maintenance?

\section{2 | INSULIN THERAPY AND WEIGHT}

\section{1 | Causes}

People using insulin therapy for type 2 diabetes gain weight. It can be seen both in insulin-naïve people who initiate insulin therapy and in insulin users with poor glycaemic control who intensify therapy. This weight gain is a well-known phenomenon that has been described extensively. ${ }^{8}$ For instance, Balkau et al $^{9}$ showed an average of $1.78 \mathrm{~kg}$ gained during the first year after insulin initiation in people with type 2 diabetes, of whom $24 \%$ gained $\geq 5 \mathrm{~kg}$. The main reason for this weight gain was ascribed to resolution of glycosuria. ${ }^{10,11}$

Mäkimattila et $\mathrm{al}^{10}$ investigated 26 patients with type 2 diabetes who started insulin therapy. During that year, average blood glucose concentrations improved, with reduction of average $\mathrm{HbA1c}$ from $91 \mathrm{mmol} / \mathrm{mol}(10.5 \%)$ to $60 \mathrm{mmol} / \mathrm{mol}$ (7.6\%) and fasting glucose from $16 \mathrm{mmol} / \mathrm{L}(290 \mathrm{mg} / \mathrm{dL})$ to $9 \mathrm{mmol} / \mathrm{L}(160 \mathrm{mg} / \mathrm{dL})$. Individuals gained an average of $6 \mathrm{~kg}$ during that year, of which about $85 \%$ was fat. Dietary intake increased marginally by $\sim 0.1 \mathrm{MJ} / \mathrm{d}$ or $25 \mathrm{kcal} / \mathrm{d}$. Basal metabolic rate did not change during the first year after insulin initiation. When basal metabolic rate was normalized to weight, it decreased by only $5 \%$. The majority of the weight gained by patients was explained by resolution of their glycosuria. Once plasma glucose exceeds $10 \mathrm{mmol} / \mathrm{L}(180 \mathrm{mg} / \mathrm{dL})$, it exceeds the maximum glucose reabsorption capacity of the kidney and glycosuria ensues. As seen in Figure 1, the amount of glycosuria is linearly associated with the level of glucose. For illustration, if our index case patient had his HbA1c lowered from $92 \mathrm{mmol} / \mathrm{mol}$ (10.6\%) to $53 \mathrm{mmol} / \mathrm{mol}$ (7\%), daily glycosuria would decrease from $2 \mathrm{MJ} / \mathrm{d}$ or $470 \mathrm{kcal} / \mathrm{d}$ to none.

As no adjustment in food intake was seen in those patients despite that sizable decrease in energy expenditure, weight inevitably increased. The reason for the lack of involuntary reduction of food intake is not clear. Not surprisingly, the main risk factor for weight gain in patients using insulin is the average glucose or $\mathrm{HbA1c}$ before

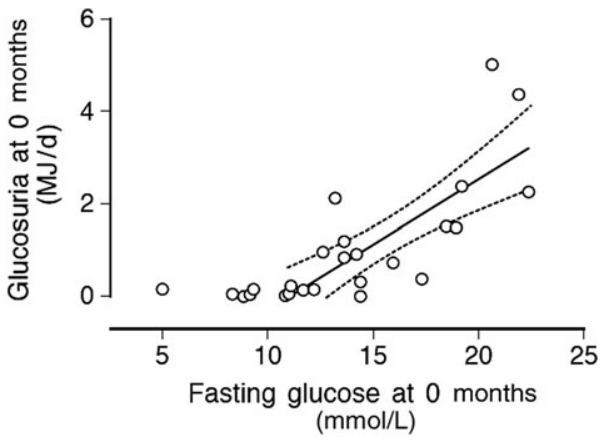

FIGURE 1 Relationship between fasting glucose and glycosuria in people with type 2 diabetes who use insulin. The $x$-axis denotes fasting glucose in $\mathrm{mmol} / \mathrm{L}$ and the $y$-axis denotes glucosuria in $\mathrm{MJ} / \mathrm{d}$. Each dot represents a single patient. Reproduced from Mäkimattila et al $^{10}$

insulin is initiated. ${ }^{9}$ That is, the higher the pre-therapy $\mathrm{HbA1c}$ level, the greater the pre-therapy glycosuria, therefore, more weight will be gained once therapy starts. Approximately 1 year into insulin therapy, weight gain is slightly affected by insulin dosage, but dosage level was $\sim 4$ times less impactful than pre-treatment HbA1c. Weight gain is not associated with $\mathrm{HbA} 1 \mathrm{c}$ changes during the treatment or with the HbA1c achieved 1 year after insulin therapy is started. ${ }^{9,12}$ Interestingly, sustaining glycosuria with SGLT2 inhibitors for 1 year in patients using insulin, was shown to induce $\sim 3 \mathrm{~kg}$ weight loss ${ }^{13}$; however, it was unclear if the people in the control group who were treated with insulin alone gained weight during that year.

\section{2 | Is this a self-perpetuating cycle?}

Because patients using exogenous insulin gain weight, and weight gain promotes an increase in insulin requirements, a self-perpetuating cycle may potentially be involved. Is that a considerable contributing factor for weight gain in these patients? The $4 \mathrm{~T}$ trial (Holman et $\mathrm{al}^{14}$ ) can give the answer. The trial enrolled 708 insulin-naive people with type 2 diabetes just as they required initiation of insulin therapy for glycaemic management. Three different insulin regimens were randomized and compared for a period of 3 years. Figure 2 shows the dynamics in body weight (Figure $2 \mathrm{~A}$ ) and total daily insulin dosage per kg of body weight (Figure 2B). Total daily insulin rose steadily during the first 2 to 2.5 years after insulin initiation. By contrast, body weight rose by $\sim 6 \mathrm{~kg}$ during the first 0.5 to 1 year, when it levelled. The difference between the two plateaus was 1.5 years. These results do not support an association between weight gain and insulin dosage; a selfperpetuating cycle is improbable.

Interestingly, although total daily insulin started at $\sim 0.2 \mathrm{unit} / \mathrm{kg}$, after 3 years of insulin therapy, it was as high as $\sim 1$ unit $/ \mathrm{kg}$. The average BMI in the participants in the $4 \mathrm{~T}$ study was $\sim 30 \mathrm{~kg} / \mathrm{m}^{2}$ and the duration of diabetes was $\sim 9$ years. In studies that follow patients with longer disease duration and higher body weight, higher total daily insulin can be seen. For example, Bergental et al ${ }^{15}$ followed 273 patients with a disease duration of $\sim 13$ years and a BMI of $\sim 36 \mathrm{~kg} / \mathrm{m}^{2}$. They compared two methods of basal-bolus insulin therapy, with and without carbohydrate counting. After a follow-up of 


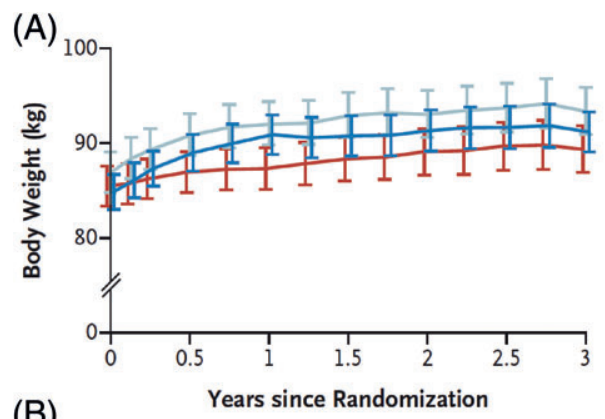

(B)

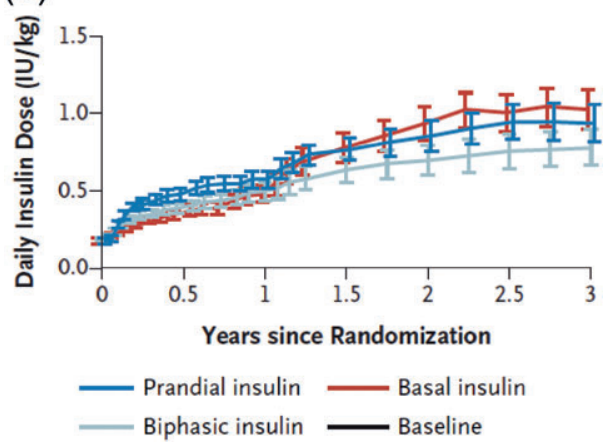

FIGURE 2 Dynamics in body weight and total daily insulin over a period of 3 years in people with type 2 diabetes who initiated insulin therapy. A, Body weight in kg. B, Total daily insulin normalized to body weight in units per kg. Each line represents a different type of insulin regimen. Reproduced from Holman et $\mathrm{al}^{14}$

24 weeks that included intensive dosage optimization, total daily insulin was as high as $\sim 1.8$ units per kg per day.

\section{3 | Natural history of weight}

Another pertinent piece of information is the natural history of the weight trajectory in adults without diabetes. The relative magnitude of $\sim 5 \mathrm{~kg}$ weight gain is greater if patients are expected to maintain stable weight and lower if weight is expected to increase over time. Surprisingly, data showing weight changes in healthy individuals are scant. One of the few reports can be seen in the CARDIA study. Over a period of 20 years, Hankinson et $\mathrm{al}^{16}$ followed 3554 healthy individuals aged 18 to 30 years. On average, both men and women gained weight steadily, in the order of $\sim 1 \mathrm{~kg}$ per year, unrelated to physical activity (Figure 3 ). Higher weight gain was seen in individuals with a higher baseline BMI, but this observation was not accompanied by reported statistical difference. ${ }^{17}$

Intriguingly, while patients starting insulin gain weight, before starting insulin they are expected to lose weight through catabolism of protein and fat. ${ }^{18,19}$ Larger et $\mathrm{al}^{20}$ compared weight changes in 58 patients during the first 3 years after insulin initiation to the weight loss before it. The level of weight gained after insulin initiation was similar to the weight lost before insulin initiated.

In conclusion, insulin therapy is indirectly associated with $~ 5 \%$ weight gain or regain, which may or may not exceed the expected individual weight trajectory.

\section{3 | WEIGHT AND PROGNOSIS}

In healthy adults, weight and prognosis demonstrate a U-shaped relationship. ${ }^{21,22}$ This has been shown in a meta-analysis by the Global BMI Mortality Collaboration. ${ }^{22}$ In that study, a 14-year follow-up of 10625411 healthy adults showed a U-shaped relationship. All-cause mortality rose when BMI exceeded $25 \mathrm{~kg} / \mathrm{m}^{2}$ or when BMI descended below $20 \mathrm{~kg} / \mathrm{m}^{2}$. Does this $U$-shaped relationship hold true in patients with already diagnosed type 2 diabetes?

\section{1 | In prediabetes or newly diagnosed diabetes}

Two main interventional studies explored the metabolic benefits in intensive lifestyle intervention that included weight loss, during the prediabetic or early diabetes stages. In both cases, interventions were supported by medical personnel. The Diabetes Prevention Program (DPP) study randomized 3234 adults with prediabetes into a lifestyle modification programme, metformin or placebo. The lifestyle modification programme enabled individuals to lose $\sim 5 \%$ of their total body weight, some of which was regained in the subsequent 4 years. ${ }^{23}$ In that group, a significant delay in the diagnosis of diabetes was seen compared with the control group, but no cardiovascular or survival benefit was seen during the trial or in the long-term follow-up. ${ }^{24}$ The LOOK AHEAD study ${ }^{25}$ explored the benefit of lifestyle intervention in diabetes remission. A total of 5145 adults with diabetes of $\sim 5$ years' duration ( $<20 \%$ treated with insulin at baseline) were randomized into either intensive lifestyle intervention or diabetes support and
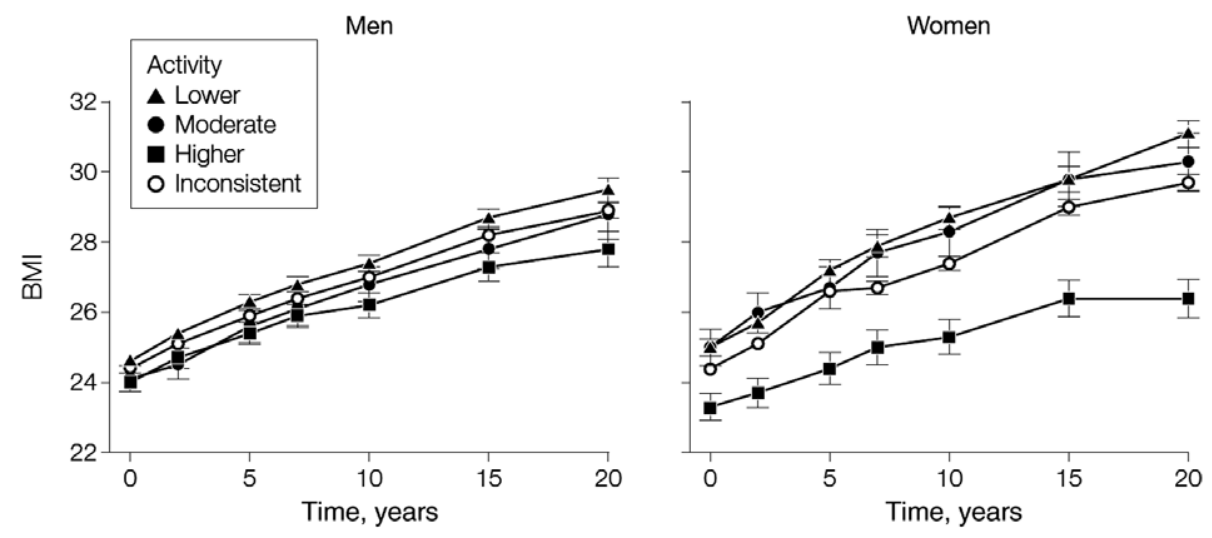

FIGURE 3 Natural history of weight in healthy individuals over a period of 20 years. The $x$-axes denote time in years and the $y$-axes denote body mass index $(\mathrm{BMI})$ in $\mathrm{kg} / \mathrm{m}^{2}$. Each line represents patients with a different level of physical activity. Reproduced from Hankinson et al ${ }^{16}$ 
education. In the intensive lifestyle intervention group, weight decreased by $\sim 9 \%$ of body weight during the first year, of which half was regained by the end of the 4-year follow-up. By the end of the 4 years, $\sim 4 \%$ of the individuals in the intensive group were able to maintain remission from diabetes and no survival or cardiovascular implications were reported. Nevertheless, none of these trials were clearly powered to assess prognosis.

In a cross-sectional study, Cho et $\mathrm{al}^{26}$ investigated the relationship between cardiovascular morbidity and mortality and weight changes before the development of diabetes in 5897 women with type 2 diabetes over a period of $\sim 20$ years. Although weight and weight gain before the diagnosis of type 2 diabetes were strongly associated with cardiovascular morbidity and mortality, weight and weight changes after the diagnosis were not.

In a small retrospective analysis of death certificates of 233 individuals with type 2 diabetes, Lean et $\mathrm{al}^{27}$ investigated the impact of weight loss during the first year after the diagnosis on overall mortality. Although BMI was not associated with prognosis, weight loss during the first year of diagnosis was associated with longer survival.

\section{2 | In prevalent diabetes}

The picture changes completely in patients with prevalent diabetes (ie, already diagnosed diabetes). The data are extensive, therefore, a sample only is presented here. As expected, the data are taken from cross-sectional non-interventional studies. Carnethon et $a^{28}$ pooled analyses from five longitudinal cohort studies to investigate the effect of initial BMI on overall mortality. Data from 2625 individuals with new-onset diabetes in adulthood (age at diagnosis $\sim 60$ years) were cumulatively followed for 27125 person-years. Although no description of diabetes type was given, the majority of the individuals were expected to have had type 2 diabetes. The report does not indicate how many of these patients were using insulin. When divided based on initial BMI, compared with individuals who were overweight or obese (BMI $>25 \mathrm{~kg} / \mathrm{m}^{2}$ ), a follow-up of $\sim 15$ years showed a $\sim 25 \%$ statistically significant decrease in overall survival in individuals with normal weight (BMI 18.5-24.9 kg/m²; Figure 4). Cardiovascular mortality was not significantly different. Subgroup analysis continued to show the same difference in overall mortality in any of the subgroups, adjusted to sex, race, age (> or $<65$ years) or smoking history.

In the TRIAD study, McEwen et $\mathrm{al}^{29}$ explored the factors affecting mortality in people with prevalent diabetes. A total of 8733 people with prevalent diabetes were followed for $\sim 4$ years. Although no description of diabetes type was given, the majority of the participants were expected to have had type 2 diabetes (age of recruitment $\sim 65$ years) At baseline, $31 \%$ of the participants were treated with insulin. In that cohort, participants were divided according to their initial BMI. When compared with overweight participants (BMI $\geq 26$ to $<30 \mathrm{~kg} / \mathrm{m}^{2}$ ), those with a $\mathrm{BMI}<26 \mathrm{~kg} / \mathrm{m}^{2}$ had a statistically worse prognosis. Compared with overweight, normal weight (BMl $\left.<26 \mathrm{~kg} / \mathrm{m}^{2}\right)$ was associated with a $43 \%$ (adjusted) increase in overall mortality and a $50 \%$ increase in cardiovascular mortality (adjusted). BMI $\geq 30 \mathrm{~kg} / \mathrm{m}^{2}$ did not affect outcomes.

The positive relationship between BMI and prognosis (ie, the higher the $\mathrm{BMI}$, the better the prognosis) remains in the older

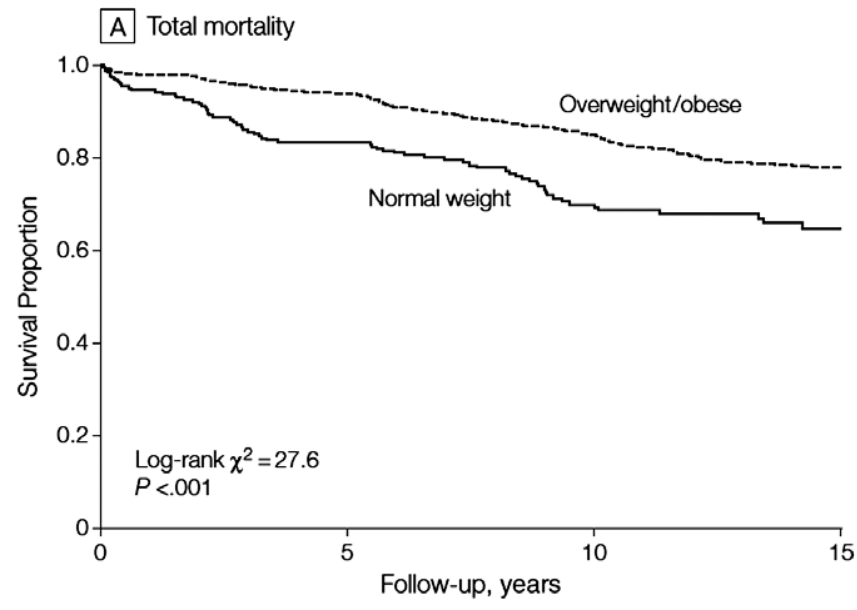

FIGURE 4 The association between body mass index (BMI) and prognosis in people with diabetes. The $x$-axis denotes time in years and the $y$-axis denotes survival as a fraction of the total. Each line represents people with a different BMI category. Reproduced from Carnethon et $\mathrm{al}^{28}$

population. In the AGES-Reykjavik study, Murphy et $\mathrm{al}^{30}$ investigated the relationship between $\mathrm{BMI}$ and mortality in an elderly population. A total of 634 people with type 2 diabetes, aged 66 to 96 years, were followed over a period of $\sim 7$ years. At baseline, $~ 10 \%$ were treated with insulin. Compared with initially overweight individuals (BMI $25-29.9 \mathrm{~kg} / \mathrm{m}^{2}$ ), individuals of normal weight (BMI $18.5-24.9 \mathrm{~kg} / \mathrm{m}^{2}$ ) had a $72 \%$ higher adjusted overall mortality rate. Obesity $\left(\mathrm{BMI} \geq 30 \mathrm{~kg} / \mathrm{m}^{2}\right)$ did not affect prognosis. Notably, both in the overweight and obese groups, BMI seems to increase, beginning in midlife, although the publication did not provide statistical confirmation for this observation.

In a recent publication, Anyanwagu et $\mathrm{al}^{31}$ investigated the relationship between weight changes and prognosis in 18814 individuals with insulin-treated type 2 diabetes. Over a period of $\sim 4$ years, overall mortality was significantly higher in individuals who lost $>5 \mathrm{~kg}$. Other changes in weight did not affect prognosis.

\section{3 | The obesity paradox}

Although initially surprising, the positive relationship between weight, weight gain and prognosis (ie, the higher the weight, the better the prognosis) has been shown in other chronic medical conditions, including coronary artery disease, ${ }^{32}$ congestive heart failure ${ }^{33}$ and advanced renal failure. ${ }^{34}$

Thomas et $\mathrm{al}^{35}$ investigated the type 2 diabetes obesity paradox in two different cohorts of patients: one with known cardiovascular morbidity at the time of diabetes diagnosis ( $n=10237$ ) and one without cardiovascular morbidity at the time of diagnosis ( $n=37272$ ). The participants were followed for $\sim 5$ years. The obesity paradox was apparent in both cohorts, with similar relative increments in mortality risk. Based on their BMI at the time of diagnosis, in participants without cardiovascular morbidity, the overall mortality rate was 13.1 per 1000 participant-years in those with normal weight, 8.6 per 1000 participant-years in overweight individuals and 6 per 1000 participant-years in obese individuals. Among participants with known cardiovascular disease, overall mortality was 30.1 per 1000 
participant-years in those of normal weight, 21.1 per 1000 participant-years in overweight participants and 15.4 per 1000 participant-years in obese participants. These data imply that the diabetes obesity paradox is independent of the cardiovascular obesity paradox.

Does the obesity paradox apply to all stages of diabetes? This question is particularly important given the progressive nature of the disease and our specific interest in people with advanced diabetes.

The KOMERIT study (Lee et $\mathrm{al}^{36}$ ) was designed to answer the question in 12815006 individuals with diabetes (the majority were expected to have had type 2 diabetes). It provides insights as to the existence of the obesity paradox in different stages of insulin deficiency. Participants were followed for $\sim 10.5$ years. The U-shaped curve illustrating the relationship between overall mortality and BMI was clearly seen in participants without diabetes (Figure 5); however, as insulin deficiency progressed through impaired fasting glucose, new-onset diabetes and prevalent diabetes, the ascending limb of the $\mathrm{BMI} /$ mortality curve gradually flattened. Although details pertaining to insulin therapy were not provided, the study implies that the weight paradox progresses as insulin deficiency progresses.

Taking these results together, in people with advanced diabetes, higher weight or weight gain is not associated with worse prognosis.

\section{4 | INSULIN THERAPY AND PROGNOSIS}

\section{1 | Safety}

Insulin as a therapy has been used for almost a century, yet it is still feared by many clinicians. In fact, insulin has a relatively favourable safety profile. Compared with all other agents used for the management of diabetes, insulin formulations do not have upper dosage limits and have only one source of toxicity: namely hypoglycaemia.

Several studies have highlighted the safety aspect of insulin therapy. The ORIGIN study by Gerstein et al ${ }^{37}$ evaluated the outcomes of early introduction of insulin glargine in a population not typically treated with insulin therapy. A total of 12537 insulin-naïve patients with a relatively early stage of type 2 diabetes or prediabetes $(\sim 5.5$ years with diabetes) were assigned to be treated with insulin glargine vs control and followed for a period of $\sim 6$ years. Probably as a result of effective residual insulin secretion, total daily insulin was low at 0.4 unit $/ \mathrm{kg} / \mathrm{d}$. After 6 years, insulin glargine did not increase the risk of cardiovascular, cancer or other life-threatening conditions.

In the DIGAMI study, Malmberg et $\mathrm{al}^{38}$ investigated the outcomes of insulin therapy introduced during the most vulnerable cardiovascular state that exists, namely acute myocardial infarction. A total of 620 people with diabetes ( $80 \%$ with type 2 diabetes and approximately one-third already treated with insulin) were assigned either to 3 months of intensive insulin therapy or to standard antihyperglycaemic care at the discretion of the physician in charge. In the intensive group, insulin therapy was already introduced in the intensive care unit as intravenous insulin infusion, followed by multiple daily insulin injections. By the end of the first year, $\mathrm{HbA} 1 \mathrm{c}$ reduction was statistically more pronounced in the intensive insulin therapy group than in the standard anti-hyperglycaemic therapy group $(-1.3 \%$

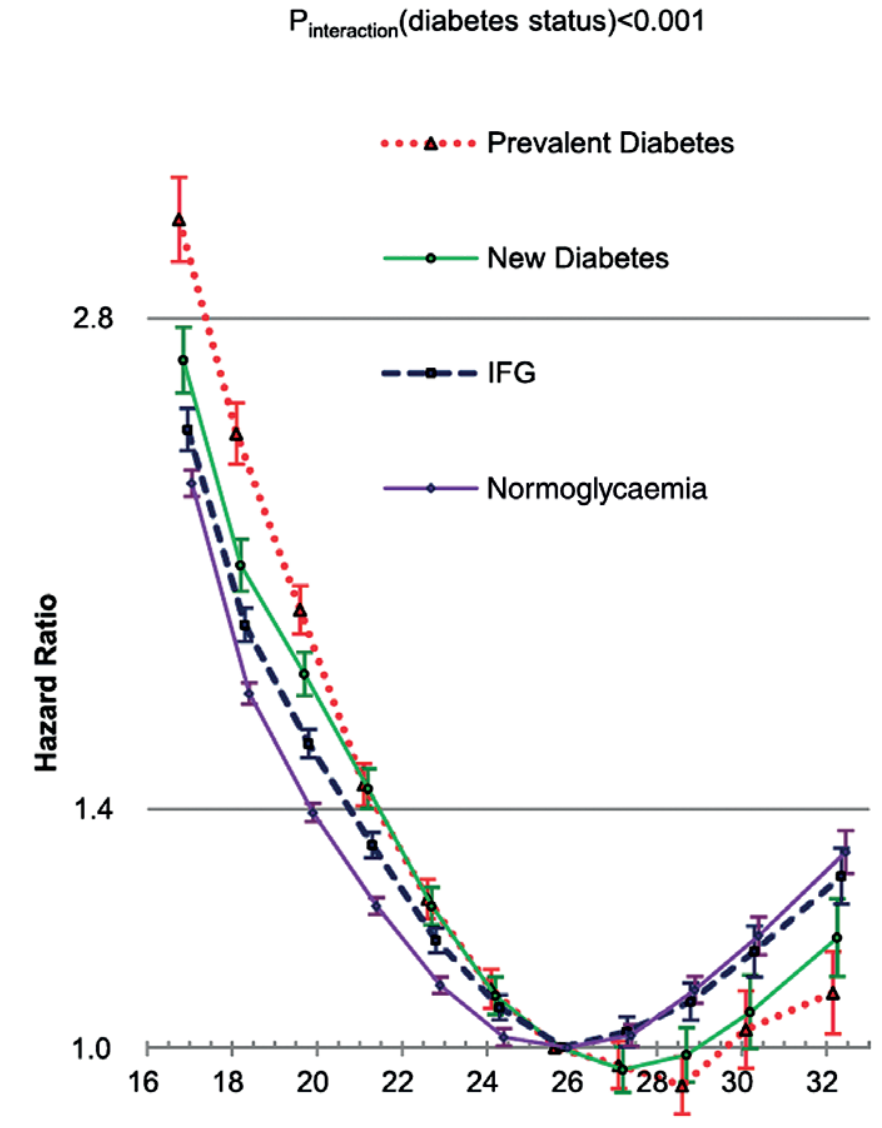

$P_{\text {interaction }}$ (diabetes status) $<0.001$

$\cdots \Delta \cdots$ Prevalent Diabetes

0.7

FIGURE 5 The association between body mass index (BMI) and prognosis in different stages of insulin deficiency. The $x$-axis denotes $\mathrm{BMI}$ in $\mathrm{kg} / \mathrm{m}^{2}$ and the $y$-axis denotes hazard ratio for all-cause mortality. Each line represents individuals with different stages of insulin deficiency. Reproduced from Lee et al. ${ }^{36}$ Abbreviation: IFG, impaired fasting glucose

vs $-0.4 \%$, respectively). After a follow-up of 3.4 years, overall relative mortality was $28 \%$ lower in the intensive insulin-treated group compared with the control group, particularly in patients who were admitted with higher glucose levels. The beneficial affect lasted during the 7.3 years follow-up phase. ${ }^{39}$ The safety of introduction of insulin therapy during the early post-infarction period was shown in the DIGAMI 2 study, although no prognostic benefit was shown. ${ }^{40}$

Severe hypoglycaemia is the main feared consequence of insulin therapy. But how dangerous is it? Looking at cumulative data from three large studies over the past decade, namely, ACCORD, ${ }^{41}$ ADVANCE $^{42}$ and VADT, ${ }^{43}$ the frequency of severe hypoglycaemia was $\sim 4$ per 100 participant-years. Conversely, the frequency of fatal or near-fatal severe hypoglycaemic events was as low as $\sim 0.003$ per 100 participant-years. Cumulatively in all study groups, all-cause mortality was 1.4 per 100 participant-years; therefore, for each individual who dies from severe hypoglycaemia, hundreds die from other conditions, many of which are related to diabetes and are potentially preventable. This information does not mean that severe hypoglycaemia is a mild event that can be ignored. On the contrary, we should do all 
we can to prevent it. Yet, by no means should hypoglycaemia discourage us from prescribing or intensifying insulin therapy. Realistically, risk of fatal or near-fatal severe hypoglycaemia is as low as the risk of developing metformin-related lactic acidosis. ${ }^{44}$ Interestingly, a higher dosage of insulin was not found to be a risk factor for severe hypoglycaemia, ${ }^{45}$ nor has it been shown to increase mortality. ${ }^{46}$

\section{2 | Prognostic effect}

The UK Prospective Diabetes Study (UKPDS) can provide some information about the effect of insulin therapy on prognosis. ${ }^{47}$ The trial was designed to determine the relationship between hyperglycaemic exposure and prognosis in people with type 2 diabetes. A total of 3867 individuals with newly diagnosed diabetes were enrolled. The trial was designed as an intervention with individuals randomized to the initial mode of therapy, but the subsequent mode of therapy over the 10 -year follow-up was left to the discretion of patients' providers, whose treatment regimens were highly diverse. This was by no means an insulin therapy study, and insulin use is not clearly documented in the UKPDS publications; however, it is likely that, by the end of the study, many of the participants were being treated with insulin, whether they were assigned to the intensive group (fasting glucose $\leq 6 \mathrm{mmol} / \mathrm{L}[108 \mathrm{mg} / \mathrm{dL}$ ) or control group (fasting glucose $\leq 15 \mathrm{mmol} / \mathrm{L}$ [270 mg/dL]). The most successful group in terms of complications prevention was the metformin-first arm of the intensive group. Overall mortality and morbidity related to diabetes was statistically and linearly linked with HbA1c. For each $10-\mathrm{mmol} / \mathrm{mol}$ (1\%) reduction in updated $\mathrm{HbA1c}$, adjusted overall mortality decreased by $14 \%$ and diabetes-related death by $21 \%$. Updated HbA1c denotes average $\mathrm{HbA} 1 \mathrm{c}$ across the study.

The CREDIT study provides the most specific information about the influence of insulin replacement on prognosis in people with type 2 diabetes. In this non-interventional prospective trial, Freemantle et $\mathrm{al}^{48}$ followed 2999 individuals with long-standing type 2 diabetes ( 9 years' duration) who started insulin therapy. Participants were recruited from different continents including Europe, North America and Asia. In the 4-year follow-up, average $\mathrm{HbA1c}$ improved from $\sim 80 \mathrm{mmol} / \mathrm{mol}(9.5 \%)$ to $\sim 60 \mathrm{mmol} / \mathrm{mol}(7.6 \%)$. In that study, updated $\mathrm{HbA} 1 \mathrm{c}$ denoted adjusted $\mathrm{HbA} 1 \mathrm{c}$ across the study except for the first 1 month. As expected, during the first year following insulin initiation, participants gained an average of $1.78 \mathrm{~kg}$ and $24 \%$ of participants gained $\geq 5 \mathrm{~kg}$. ${ }^{9}$ Noteworthy were participants' baseline characteristics. Before initiating insulin therapy, $50 \%$ of the participants had $\mathrm{HbA} 1 \mathrm{c}$ $>78 \mathrm{mmol} / \mathrm{mol}$ (9.3\%) and $25 \%>93 \mathrm{mmol} / \mathrm{mol}$ (10.7\%). These baseline characteristics seem remarkably poor, yet they are strikingly similar to the current reality. Across nations in the Western world, average $\mathrm{HbA} 1 \mathrm{c}$ in insulin-treated people is $\sim 69 \mathrm{mmol} / \mathrm{mol}(8.5 \%)$. Two-thirds of these people have an HbA1c above the goal of $\sim 53 \mathrm{mmol} / \mathrm{mol}(7 \%)$ and one-third live with $\mathrm{HbA1c}>75 \mathrm{mmol} / \mathrm{mol}$ (9\%). ${ }^{1,4}$ This poor profile has not changed for the past three decades.

By the end of the 4-year follow-up of the CREDIT study, for each $10-\mathrm{mmol} / \mathrm{mol}$ reduction of updated $\mathrm{HbA} 1 \mathrm{c}(1 \%)$, cardiovascular morbidity was reduced by $25 \%$ and cardiovascular mortality reduced by $31 \%$. It seems that in participants with advanced type 2 diabetes, insulin deprivation is highly toxic in the short term. These data indicate that for the index patient presented in the beginning of the present review, if insulin therapy reduces $\mathrm{HbA} 1 \mathrm{c}$ from $93 \mathrm{mmol} / \mathrm{mol}$ (10.6\%) to be maintained at $7 \%(53 \mathrm{mmol} / \mathrm{mol})$ over a period of 4 years, the risk of cardiovascular morbidity is reduced by $\sim 84 \%$ and cardiovascular mortality by $~ 89 \%$.

Taken together, adequate insulinization conceivably prevents cardiovascular morbidity and mortality.

\section{3 | Mechanistics}

The strong effect of adequate insulinization on prognosis exhibited in the CREDIT study warrants additional discussion in view of several large clinical studies over the past decade. In both ACCORD $^{41}$ and ADVANCE, ${ }^{42}$ intensive $\mathrm{HbA} 1 \mathrm{c}$ goals ( $\left.48 \mathrm{mmol} / \mathrm{mol}[6.5 \%]\right)$ were compared with less intensive goals $(\sim 58 \mathrm{mmol} / \mathrm{mol}[7.5 \%])$ to be attained using a variety of pharmacological agents. Cumulatively, for the duration of these studies, which each lasted $\sim 5$ years, no advantage in mortality or cardiovascular morbidity was seen. ${ }^{49}$ Because the ADVANCE, ACCORD and CREDIT studies were all methodologically sound, it is important to explore the apparent dramatic difference in their results.

Unlike the CREDIT study, the ACCORD/ADVANCE studies used multiple pharmacological agents rather than focusing exclusively on the effect of insulin therapy on prognosis. In addition, contrary to the wide baseline $\mathrm{HbA} 1 \mathrm{c}$ distribution of the CREDIT study (median \pm interquartile range $78 \pm 13 \mathrm{mmol} / \mathrm{mol}[9.3 \pm 1.3 \%]$ ) in which $50 \%$ of patients began with $\mathrm{HbA} 1 \mathrm{c}>78 \mathrm{mmol} / \mathrm{mol}(9.3 \%)$, only $16 \%$ of participants in the ACCORD and ADVANCE studies had HbA1c above this value at the time of enrolment. The main dissimilarity between the CREDIT and the ACCORD/ADVANCE studies, however, was the scientific question being asked.

Being interventional studies, the ACCORD/ADVANCE studies aimed to compare two different therapeutic goals, more intensive $\mathrm{HbA1c}$ and less intensive HbA1c; whether participants achieved the therapeutic effect or not was immaterial. For example, if in the ACCORD/ADVANCE study a participant did not decrease his/her $\mathrm{HbA1c}$ to the goal of the study arm, he/she would still continue being followed in that arm regardless. Furthermore, based on the protocol, he/she would have been offered more pharmacological classes. ${ }^{50}$ Whereas the CREDIT study, being a non-interventional prospective study, examined the relationship between $\mathrm{HbA} 1 \mathrm{c}$ achieved and a prognosis unrelated to the therapy goal. For example, a participant would be counted as having therapeutic $\mathrm{HbA1c}$ or non-therapeutic HbA1c only if he/she has actually achieved it.

Supporting the assertion that the difference in the scientific questions was the cause for the difference in the results is a sub-analysis that applied the CREDIT methodology to the results of the ACCORD study. ${ }^{51}$ Accumulating participants from all the ACCORD study arms, a $1 \%$ lower average $\mathrm{HbA1C}$ during the study was associated with $45 \%$ adjusted lower all-cause mortality. This relationship was statistically significant.

The notion that $\mathrm{HbA1c}$, or average glycation, has prognostic value in people using insulin does not mean that hyperglycaemia is the only source of damage. Although we monitor the success of the therapy with $\mathrm{HbA1c}$, the function of the insulin/insulin receptor system extends beyond glucose homeostasis. The receptor affects de novo lipogenesis, plasma clearance of apolipoproteins, endothelin- 
1-mediated vasoconstriction and nitrous oxide-mediated vasodilation, all of which may affect both the macrovascular and microvascular domains. ${ }^{52}$

Until lately, the most widely accepted mechanism explaining endorgan damage in people with diabetes was the advanced glycation endproducts concept (reviewed by Piarulli et $\mathrm{al}^{53}$ ). Essentially, the damage increases in direct relation to the duration and intensity of hyperglycaemia as a result of glycation of proteins and fat. Over the past decade, data have been accumulated to show that the lack of insulin signalling causes damage unrelated to the level of glucose. Rask-Madsen et $\mathrm{al}^{54}$ investigated atheroma development in atherosclerosis-prone mice (apolipoprotein $\mathrm{E}$ knockout). In a subset of mice, the insulin receptor gene was conditionally knockout only in endothelial cells and compared to controls with full competence of the insulin receptor. Despite the fact that all mice were euglycaemic and had a similar lipid profile, the ones who lacked the insulin signalling in endothelial cells developed atherosclerosis at a rate that was three times as widespread as that of controls.

Han et $\mathrm{al}^{55}$ also investigated atheroma development in atherosclerosis-prone mice (low-density receptor knockout). In a subset of mice, the insulin receptor gene was selectively knocked out in macrophages compared with mice with full competence of the insulin receptor. Despite comparable glycaemia in both groups, mice with insulin receptor deficiency in macrophages did not only have more atherosclerotic plaque but the plaque was unstable with twice as much necrotic core.

Welsh et al ${ }^{56}$ investigated mice who were conditionally knockout to the insulin receptor gene in the kidney podocyte. Again, despite euglycaemia, podocyte insulin receptor knockouts had $>5$ times more proteinuria compared with controls. Interestingly, people with insulin receptor mutations, and thus complete loss of insulin signalling, tend to have exceptionally progressive nephropathy. ${ }^{57}$

\section{5 | CONCLUSIONS}

The body of evidence presented in this review indicates that, in people with insulin-treated type 2 diabetes, the benefits of glycaemic management with exogenous insulin replacement are of a much higher priority than weight gain. It is probable that lower weight or weight loss are markers of insulin deficiency or overall morbidity rather than the cause of inferior prognosis. Lower weight or weight loss do not show prognostic benefit in advanced stages of diabetes; therefore, weight gain should not discourage providers from achieving and maintaining HbA1c goals with insulin therapy, regardless of insulin dosage or other medications. Depriving patients of full insulin replacement, which unfortunately often occurs, is exceedingly detrimental.

As far as the index patient is concerned, the best approach would be to intensify his insulin replacement therapy using average glucose (HbA1c) as a clinical guide for insulin availability. As the patient has had high $\mathrm{HbA1c}$ for years before re-insulinization, he is likely to gain at least $5 \mathrm{~kg}$. The patient should be reassured that the expected weight gain does not by any means impede the therapeutic advantages of exogenous insulin therapy.

\section{Conflict of interest}

I.H. is a co-founder of Hygieia Inc.

\section{ORCID}

Israel Hodish (D) http://orcid.org/0000-0001-8174-384X

\section{REFERENCES}

1. Selvin E, Parrinello CM, Daya N, Bergenstal RM. Trends in insulin use and diabetes control in the U.S.: 1988-1994 and 1999-2012. Diabetes Care. 2016;39(3):e33-e35.

2. Lipska KJ, Yao X, Herrin J, et al. Trends in drug utilization, glycemic control, and rates of severe hypoglycemia, 2006-2013. Diabetes Care. 2017;40(4):468-475.

3. UCFHR M. The United States of Diabetes: challenges and opportunities in the decade ahead. 2010. http://www.unitedhealthgroup.com/ /media/uhg/pdf/2010/unh-working-paper-5.ashx. Accessed June 15, 2018.

4. Juarez DT, Ma C, Kumasaka A, Shimada R, Davis J. Failure to reach target glycated a1c levels among patients with diabetes who are adherent to their antidiabetic medication. Popul Health Manag. 2014; 17:218-223.

5. Mokdad AH, Ford ES, Bowman BA, et al. Prevalence of obesity, diabetes, and obesity-related health risk factors, 2001. JAMA. 2003;289:76-79.

6. Garber AJ. Obesity and type 2 diabetes: which patients are at risk? Diabetes Obes Metab. 2012;14:399-408.

7. Seeley RJ, Chambers AP, Sandoval DA. The role of gut adaptation in the potent effects of multiple bariatric surgeries on obesity and diabetes. Cell Metab. 2015;21:369-378.

8. Russell-Jones D, Khan R. Insulin-associated weight gain in diabetes-causes, effects and coping strategies. Diabetes Obes Metab. 2007;9:799-812.

9. Balkau B, Home PD, Vincent M, Marre M, Freemantle N. Factors associated with weight gain in people with type 2 diabetes starting on insulin. Diabetes Care. 2014;37:2108-2113.

10. Makimattila S, Nikkila K, Yki-Jarvinen $\mathrm{H}$. Causes of weight gain during insulin therapy with and without metformin in patients with type II diabetes mellitus. Diabetologia. 1999;42:406-412.

11. Standards of medical care in diabetes. Diabetes Care. 2011;34(suppl 1):S11-S61.

12. Biesenbach G, Raml A, Alsaraji N. Weight gain and insulin requirement in type 2 diabetic patients during the first year after initiating insulin therapy dependent on baseline BMI. Diabetes Obes Metab. 2006;8:669-673.

13. Neal B, Perkovic V, de Zeeuw D, et al. Efficacy and safety of canagliflozin, an inhibitor of sodium-glucose cotransporter 2 , when used in conjunction with insulin therapy in patients with type 2 diabetes. Diabetes Care. 2015;38:403-411.

14. Holman RR, Farmer AJ, Davies MJ, et al. Three-year efficacy of complex insulin regimens in type 2 diabetes. N Engl J Med. 2009;361: 1736-1747.

15. Bergenstal RM, Johnson M, Powers MA, et al. Adjust to target in type 2 diabetes: comparison of a simple algorithm with carbohydrate counting for adjustment of mealtime insulin glulisine. Diabetes Care. 2008;31:1305-1310.

16. Hankinson AL, Daviglus ML, Bouchard C, et al. Maintaining a high physical activity level over 20 years and weight gain. JAMA. 2010;304: 2603-2610.

17. Lloyd-Jones DM, Liu K, Colangelo LA, et al. Consistently stable or decreased body mass index in young adulthood and longitudinal changes in metabolic syndrome components: the coronary artery risk development in young adults study. Circulation. 2007;115:1004-1011.

18. Nair KS, Ford GC, Ekberg K, Fernqvist-Forbes E, Wahren J. Protein dynamics in whole body and in splanchnic and leg tissues in type I diabetic patients. J Clin Invest. 1995;95:2926-2937.

19. Ramnanan CJ, Edgerton DS, Kraft G, Cherrington AD. Physiologic action of glucagon on liver glucose metabolism. Diabetes Obes Metab. 2011;13(suppl 1):118-125. 
20. Larger E, Rufat P, Dubois-Laforgue D, Ledoux S. Insulin therapy does not itself induce weight gain in patients with type 2 diabetes. Diabetes Care. 2001;24:1849-1850.

21. Iliodromiti S, Celis-Morales CA, Lyall DM, et al. The impact of confounding on the associations of different adipositymeasures with the incidence of cardiovascular disease: a cohort study of 296535 adults of white European descent. Eur Heart J. 2018;39(17):1-8.

22. Global BMI Mortality Collaboration, Di Angelantonio E, Bhupathiraju SN, et al. Body-mass index and all-cause mortality: individual-participant-data meta-analysis of 239 prospective studies in four continents. Lancet. 2016;388:776-786.

23. Knowler WC, Barrett-Connor E, Fowler SE, et al. Reduction in the incidence of type 2 diabetes with lifestyle intervention or metformin. $N$ Engl J Med. 2002;346:393-403.

24. Diabetes Prevention Program Research Group. Long-term effects of lifestyle intervention or metformin on diabetes development and microvascular complications over 15-year follow-up: the diabetes prevention program outcomes study. Lancet Diabetes Endocrinol. 2015;3:866-875.

25. Gregg EW, Chen H, Wagenknecht LE, et al. Association of an intensive lifestyle intervention with remission of type 2 diabetes. JAMA 2012;308:2489-2496.

26. Cho E, Manson JE, Stampfer MJ, et al. A prospective study of obesity and risk of coronary heart disease among diabetic women. Diabetes Care. 2002;25:1142-1148.

27. Lean ME, Powrie JK, Anderson AS, Garthwaite PH. Obesity, weight loss and prognosis in type 2 diabetes. Diabet Med. 1990;7:228-233.

28. Carnethon MR, De Chavez PJ, Biggs ML, et al. Association of weight status with mortality in adults with incident diabetes. JAMA. 2012; 308:581-590.

29. McEwen LN, Kim C, Karter AJ, et al. Risk factors for mortality among patients with diabetes: the translating research into action for diabetes (TRIAD) study. Diabetes Care. 2007;30:1736-1741.

30. Murphy RA, Reinders I, Garcia ME, et al. Adipose tissue, muscle, and function: potential mediators of associations between body weight and mortality in older adults with type 2 diabetes. Diabetes Care. 2014;37:3213-3219

31. Anyanwagu U, Mamza J, Donnelly R, Idris I. Association between insulin-induced weight change and CVD mortality: evidence from a historic cohort study of 18,814 patients in UK primary care. Diabetes Metab Res Rev. 2018;34(1). https://doi.org/10.1002/dmrr.2945 Epub 2017 Oct 19.

32. Gruberg L, Weissman NJ, Waksman R, et al. The impact of obesity on the short-term and long-term outcomes after percutaneous coronary intervention: the obesity paradox? J Am Coll Cardiol. 2002;39: 578-584.

33. Horwich TB, Fonarow GC, Hamilton MA, MacLellan WR, Woo MA, Tillisch JH. The relationship between obesity and mortality in patients with heart failure. J Am Coll Cardiol. 2001;38:789-795.

34. Kalantar-Zadeh K, Abbott KC, Salahudeen AK, Kilpatrick RD, Horwich TB. Survival advantages of obesity in dialysis patients. Am J Clin Nutr. 2005;81:543-554.

35. Thomas G, Khunti K, Curcin V, et al. Obesity paradox in people newly diagnosed with type 2 diabetes with and without prior cardiovascular disease. Diabetes Obes Metab. 2014;16:317-325.

36. Lee EY, Lee YH, Yi SW, Shin SA, Yi J. BMI and all-cause mortality in Normoglycemia, impaired fasting glucose, newly diagnosed diabetes, and prevalent diabetes: a cohort study. Diabetes Care. 2017;40: 1026-1033.

37. Gerstein HC, Bosch J, Dagenais GR, et al. Basal insulin and cardiovascular and other outcomes in dysglycemia. N Engl J Med. 2012;367: 319-328.

38. Malmberg K, Norhammar A, Wedel H, Ryden L. Glycometabolic state at admission: important risk marker of mortality in conventionally treated patients with diabetes mellitus and acute myocardial infarction: long-term results from the diabetes and insulin-glucose infusion in acute myocardial infarction (DIGAMI) study. Circulation. 1999;99:2626-2632.

39. Ritsinger V, Malmberg $K$, Martensson A, Ryden L, Wedel $H$, Norhammar A. Intensified insulin-based glycaemic control after myocardial infarction: mortality during 20 year follow-up of the randomised diabetes mellitus insulin glucose infusion in acute myocardial infarction (DIGAMI 1) trial. Lancet Diabetes Endocrinol. 2014;2:627-633.

40. Malmberg K, Ryden L, Wedel $\mathrm{H}$, et al. Intense metabolic control by means of insulin in patients with diabetes mellitus and acute myocardial infarction (DIGAMI 2): effects on mortality and morbidity. Eur Heart J. 2005;26:650-661.

41. Action to Control Cardiovascular Risk in Diabetes Study G, Gerstein HC, Miller ME, et al. Effects of intensive glucose lowering in type 2 diabetes. N Engl J Med. 2008;358:2545-2559.

42. Patel A, MacMahon S, Chalmers J, et al. Intensive blood glucose control and vascular outcomes in patients with type 2 diabetes. $N$ Engl J Med. 2008;358:2560-2572.

43. Duckworth W, Abraira C, Moritz T, et al. Glucose control and vascular complications in veterans with type 2 diabetes. N Engl J Med. 2009; 360:129-139.

44. Jones GC, Sainsbury CA. Comment on 'A justification for less restrictive guidelines on the use of metformin in stable chronic renal failure'. Diabet Med. 2015;32:287.

45. Akram K, Pedersen-Bjergaard U, Borch-Johnsen K, Thorsteinsson B. Frequency and risk factors of severe hypoglycemia in insulin-treated type 2 diabetes: a literature survey. J Diabetes Complications. 2006;20: 402-408.

46. Gamble JM, Chibrikov E, Twells LK, et al. Association of insulin dosage with mortality or major adverse cardiovascular events: a retrospective cohort study. Lancet Diabetes Endocrinol. 2017;5:43-52.

47. Stratton IM, Adler Al, Neil HA, et al. Association of glycaemia with macrovascular and microvascular complications of type 2 diabetes (UKPDS 35): prospective observational study. BMJ. 2000;321:405-412.

48. Freemantle N, Danchin N, Calvi-Gries F, Vincent M, Home PD. Relationship of glycaemic control and hypoglycaemic episodes to 4-year cardiovascular outcomes in people with type 2 diabetes starting insulin. Diabetes Obes Metab. 2016;18:152-158.

49. Ray KK, Seshasai SR, Wijesuriya S, et al. Effect of intensive control of glucose on cardiovascular outcomes and death in patients with diabetes mellitus: a meta-analysis of randomised controlled trials. Lancet. 2009;373:1765-1772.

50. Gerstein HC, Riddle MC, Kendall DM, et al. Glycemia treatment strategies in the action to control cardiovascular risk in diabetes (ACCORD) trial. Am J Cardiol. 2007;99:34i-43i.

51. Riddle MC, Ambrosius WT, Brillon DJ, et al. Epidemiologic relationships between $\mathrm{A} 1 \mathrm{C}$ and all-cause mortality during a median 3.4-year follow-up of glycemic treatment in the ACCORD trial. Diabetes Care. 2010;33:983-990.

52. Williams $\mathrm{KJ}, \mathrm{Wu} X$. Imbalanced insulin action in chronic over nutrition: clinical harm, molecular mechanisms, and a way forward. Atherosclerosis. 2016;247:225-282.

53. Piarulli F, Sartore G, Lapolla A. Glyco-oxidation and cardiovascular complications in type 2 diabetes: a clinical update. Acta Diabetol. 2013;50:101-110.

54. Rask-Madsen C, Li Q, Freund B, et al. Loss of insulin signaling in vascular endothelial cells accelerates atherosclerosis in apolipoprotein $\mathrm{E}$ null mice. Cell Metab. 2010;11:379-389.

55. Han S, Liang CP, DeVries-Seimon $\mathrm{T}$, et al. Macrophage insulin receptor deficiency increases ER stress-induced apoptosis and necrotic core formation in advanced atherosclerotic lesions. Cell Metab. 2006;3:257-266.

56. Welsh GI, Hale LJ, Eremina V, et al. Insulin signaling to the glomerular podocyte is critical for normal kidney function. Cell Metab. 2010;12: 329-340.

57. Musso C, Cochran E, Moran SA, et al. Clinical course of genetic diseases of the insulin receptor (type a and Rabson-Mendenhall syndromes): a 30-year prospective. Medicine (Baltimore). 2004;83:209-222.

How to cite this article: Hodish I. Insulin therapy, weight gain and prognosis. Diabetes Obes Metab. 2018;20:2085-2092. https://doi.org/10.1111/dom.13367 